\title{
Candida lung abscesses complicating parenteral nutrition
}

\section{B R C O'DRISCOLL, R D P COOKE, H MAMTORA, M H IRVING, A BERNSTEIN}

\author{
From the Hope Hospital, Salford
}

Pulmonary candidiasis is a rare condition that usually occurs in severely ill patients with underlying immunosuppression. The clinical diagnosis is very rarely confirmed in vivo by lung biopsy.' Total parenteral nutrition is an increasingly common technique for the management of patients with intestinal failure. Catheter related sepsis occurs in $2-11 \%$ of patients treated by total parenteral nutrition, the commonest pathogens being Candida albicans and staphylococci. ${ }^{2-5}$ Over 200 patients in the United Kingdom with long term dysfunction of the alimentary tract have been treated by parenteral nutrition at home. ${ }^{6}$ The annual rate of sepsis in patients having total parenteral nutrition at home ranges from 0.2 episodes in centres with a large experience to 0.9 episodes a patient in less experienced centres. ${ }^{6}$ We report a case of Candida pneumonitis associated with colonisation of a parenteral nutrition feeding line in an adult.

\section{Case report}

A 24 year old man developed a seminoma of the left testis in 1984. He was treated by orchidectomy and chemotherapy with radiotherapy to the para-aortic and left iliac nodes. The left kidney was found to be non-functioning and the paraaortic nodes, sigmoid colon, and left kidney were removed in November 1985. These tissues were free of tumour; the kidney showed changes of chronic pyelonephritis. In January 1986 he developed intestinal obstruction, believed to be the result of radiation fibrosis. After a laparotomy with partial small bowel resection he developed an enterocutaneous fistula and required prolonged total parenteral nutrition. During February and March 1986 he developed two episodes of septicaemia. On both occasions Staphylococcus epidermidis was grown from blood cultures and from the tip of the total parenteral nutrition line. He made a full recovery after appropriate antimicrobial treatment. Proteinuria was noted and a renal biopsy showed focal segmental endocapillary proliferative glomerulonephritis, which was attributed to sepsis, and the proteinuria cleared during four months of prednisolone treatment. Plasma urea and creatinine concentrations remained normal and the glomerular filtration rate was $42 \mathrm{ml} / \mathrm{min} / 1 \cdot 73 \mathrm{M}^{2}$ An unsuccessful attempt at closure of the fistula was made in June 1986.

In August 1986 he was transferred to the nutrition unit of Hope Hospital for further management and to be trained for home parenteral nutrition. He was rapidly established on total parenteral nutrition at home. In mid September he developed rigors, breathlessness, and bilateral pleuritic chest pain.

Address for correspondence: Dr B R C O'Driscoll, Chest Clinic, Wythenshawe Hospital, Manchester M23 9LT. (Reprints will not be available.)

He was febrile $\left(40^{\circ} \mathrm{C}\right)$ with no focal signs of infection. His white cell count was $16.7 \times 10^{9} / 1(91 \%$ neutrophils) andw haemoglobin concentration $8.6 \mathrm{~g} / \mathrm{dl}$ on admission. A chest radiograph revealed widespread small opacities, which had, not been present three weeks previously. The total parenterali nutrition line was removed and cultured. Treatment was $v$ started with intravenous flucloxacillin, gentamicin, and metronidazole. Intermittent fever up to $38.5^{\circ} \mathrm{C}$ persisted $\vec{\infty}$ however. Blood cultures taken on admission grew Candida albicans, which was also cultured from urine and from the tip of the central venous catheter. Computed tomography of the $\overrightarrow{-}$ thorax showed many opacities bilaterally (fig). A fine needle aspiration biopsy specimen was taken under radiographic guidance from a lesion in the left lung. Cytological examina $\overrightarrow{-}$ tion of the aspirate was consistent with abscess formation (foamy macrophages and inflammatory cells) and periodic acid-Schiff stains of the lung biopsy specimen showed yeastso with pseudohyphae suggesting invasive candidiasis.

After three weeks of intravenous treatment with amphotericin $\left(0.3 \mathrm{mg} / \mathrm{kg}\right.$ daily) and flucytosine $\left(30 \mathrm{mg} / \mathrm{kg} \mathrm{O}^{\circ}\right.$ twice daily) the pyrexia settled, with almost complete resolu- $\mathrm{D}$ tion on radiographs and computed tomography scans. He has subsequently recovered sufficiently to have his fistula closed.

\section{Discussion}

Although Candida albicans is frequently recovered from sputum and bronchial washings, this usually reflects asymptomatic colonisation of the upper respiratory tract. Invasive candidiasis is difficult to diagnose as serological tests for Candida antigen and antibodies are usually unhelpful, ${ }^{7}$ as in

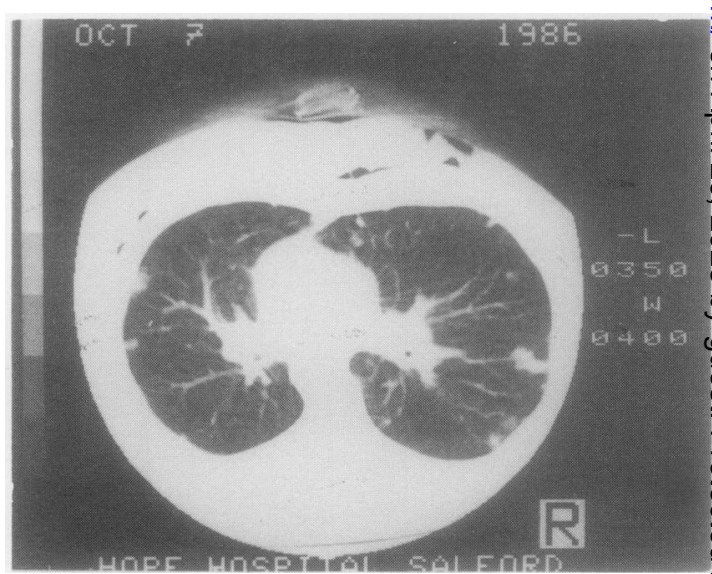

Computed tomography scan of chest before antifungal chemotherapy. 
the present case. For these reasons, lung biopsy is required to establish the diagnosis of candida pneumonitis, which is a rare disease. When it does occur it usually causes a diffuse vasculitic pneumonitis, but multiple abscesses have also been described at necropsy.' We are not aware of any previous reports of multiple candida abscesses diagnosed in vivo. In the present case detection of pseudohyphae within inflamed lung tissue supported the clinical diagnosis of candida pneumonitis and antifungal chemotherapy produced resolution of radiological shadowing, which had progressed despite three weeks of intensive antibacterial treatment.

Total parenteral nutrition feeding lines are more prone to colonisation with Candida albicans than other central venous catheters. ${ }^{23}$ Most cases of candidaemia associated with total parenteral nutrition have been asymptomatic, but clinically silent endophthalmitis (not seen in this case) is common ${ }^{2}$ and candida osteomyelitis and fatal candida septicaemia have been reported. ${ }^{4}$ It is not known why candida pneumonitis occurred in the present case. The patient had no previous history of lung disease and was not immunosuppressed, and there was no evidence of recurrence of his malignancy. Yeasts are likely to have been carried in the pulmonary artery from the colonised total parenteral nutrition line to multiple sites in the lungs. Pulmonary embolic type lesions have been described in experimental studies of total parenteral nutrition ${ }^{4}$ and lipid embolism associated with pulmonary vascular candidiasis was detected at necropsy in several infants receiving parenteral nutrition through a central venous catheter. ${ }^{8}$ In a study of 11 adults found to have pulmonary candidiasis at necropsy six cases were attributed to infected indwelling venous catheters. ${ }^{9}$ The present case of pulmonary candidiasis seems likely to have been directly attributable to infection of the parenteral nutrition feeding line. The yeasts may have colonised lung tissue that was previously damaged by lipid microembolism. If this is the case, further cases of total parenteral nutrition related candida pneumonitis are likely to be seen as the technique becomes more widely used.

We are grateful to Dr $\mathbf{R}$ Reeve for histological examination of the lung biopsy specimen and to $\mathrm{Dr} \mathbf{R} \mathbf{J}$ Hay for advice on the management of the patient and on the preparation of this manuscript.

\section{References}

1 Masur H, Rosen PP, Armstrong D. Pulmonary disease caused by candida species. Am J Med 1977;63:914-24.

2 Henderson DK, Edwards JE, Montgomerie JZ. Haematogenous candida endophthalmitis in patients receiving parenteral hyperalimention fluids. J Infect Dis 1981;143:655-61.

3 Sydnam DR, Muray SA, Kornfield SJ, Majka JA, Ellis CA. Total parenteral nutrition related infections. Prospective epidemiological study using semiquantitative methods. Am J Med 1982;73:695-9.

4 Wolfe BM, Ryder MA, Nishikawa RA, Halsted CH, Schmidt BF. Complications of parenteral nutrition. Am J Surg 1986;152: 93-9.

5 Prager RL, Silva J. Complications of central venous catheters. South Med J 1984;77:458-61.

6 Mughal M, Irving MH. Home parenteral nutrition in the United Kingdom and Ireland. Lancet 1986;ii:383-7.

7 Meunier-Carpentier F, Kiehn TE, Armstrong D. Fungaemia in the immuno-compromised host. Changing patterns, antigenaemia, high mortality. Am J Med 1981;71:363-70.

8 Knox WF, Hooton VN, Barson AJ. Pulmonary vascular candidiasis and use of central venous catheters in neonates. J Clin Pathol 1987;40:559-65.

9 Rose HD, Sheth NK. Pulmonary candidiasis: a clinical and pathological correlation. Arch Intern Med 1978;138:964-5. 